02

\title{
Рентгеноспектральные исследования межфазного взаимодействия в нанокомпозите $\mathrm{CuO}_{x} / \mathrm{MWCNTs}$
}

\author{
(C) В.А. Шматко ${ }^{1}$, А.А. Ульянкина ${ }^{2}$, Н.В. Смирнова ${ }^{2}$, Г.Э. Яловега ${ }^{1, \text { Ф }}$ \\ ${ }^{1}$ Южный фредеральный университет, \\ 344090 Ростов-на-Дону, Россия \\ ${ }^{2}$ Южно-Российский государственный политехнический университет (НПИ) им. М.И. Платова, \\ 346428 Новочеркасск, Россия \\ ฯ e-mail: yalovega1968@mail.ru
}

Поступила в редакцию 20.07.2017 г.

В окончательной редакции 12.12.2017 г.

\begin{abstract}
Представлены результаты комплексного исследования межфазного взаимодействия наноструктурированного $\mathrm{CuO}_{x}$ и многостенных углеродных нанотрубок (MWCNTs) в нанокомпозите $\mathrm{CuO}_{x} / \mathrm{MWCNT}$ методами рентгеновской спектроскопии поглощения (XANES, NEXAFS) и рентгеновской фотоэлектронной спектроскопии (XPS) с использованием синхротронного излучения. Установлено, что наноструктурированный $\mathrm{CuO}_{x}$ в нанокомпозите $\mathrm{CuO}_{x} / \mathrm{MWCNTs}$ образован преимущественно $\mathrm{CuO}$ и представляет собой равномерно диспергированные по массиву нанотрубок чешуйчатообразные частицы размером 200-500 nm. На межфазных границах нанокомпозита наблюдается химическое взаимодействие $\mathrm{CuO}_{x}$ и нанотрубок с образованием ковалентных углерод-кислородных связей, не приводящее к значительной деструкции внешних слоев углеродных нанотрубок.
\end{abstract}

DOI: $10.21883 /$ OS.2018.04.45744.168-17

\section{Введение}

Создание и исследование нанокомпозитных материалов, содержащих различные $3 d$-металлы или их оксиды, диспергированные в углеродной матрице, вызывает повышенный интерес вследствие перспектив их применения в различных областях. Материалы такого вида используются в источниках тока $[1,2]$, сенсорных устройствах [3], катализаторах [4-6]. Углеродные нанотрубки, обладая высокой механической прочностью, регулируемой электрической проводимостью и развитой пористой структурой, являются превосходным материалом для применения в качестве матрицы при создании нанокомпозитных материалов с высокой сорбционной способностью. Электропроводность наночастиц $3 d$-металлов или их оксидов возможно регулировать изменением морфологии, химического состава или кристаллической структуры [7]. Таким образом, сочетание наноструктурированных металлооксидных и углеродных компонент, в частности оксидов меди с многостенными углеродными нанотрубками (MWCNTs), позволяет получить композиты с улучшенными характеристиками [8]. Физико-химические свойства композитного материала во многом зависят как от морфологии, фазового состава составляющих композита, так и от природы взаимодействия металлооксидной составляющей с матрицей [9]. Взаимодействие между многостенными углеродными нанотрубками и оксидами металлов может приводить к изменению локальной атомной и электронной структуры обоих компонент нанокомпозита. Тип взаимодействия между оксидами металлов и стенками MWCNTs (физический или химический) влияет на физико-химические свойства композита в целом. Так, образование химической связи между наноразмерными металлооксидными частицами и углеродными трубками в гибридных материалах значительно повышает перенос заряда в электродах по сравнению с чистыми наночастицами, что указывает на перенос электронов от кислорода к металлу в таких материалах [2]. Эти результаты подтверждают, что взаимодействие между компонентами композита может существенно повлиять на функциональную активность материалов.

Уникальными методами, позволяющими исследовать особенности химической связи между атомами наноструктурированных оксидов и атомами углерода нанотрубок являются рентгеноспектральные методы: спектроскопия рентгеновского поглощения в ближней области (NEXAFS, XANES) и рентгеновская фотоэлектронная спектроскопия (XPS). Применение спектроскопических методов высокого разрешения позволяет получить информацию об особенностях атомного и электронного строения нанокомпозитов, типе химического взаимодействия их составляющих [10-14].

Целью настоящей работы являлось исследование межфазного взаимодействия медьоксидной и углеродной составляющих при формировании $\mathrm{CuO}_{x} / \mathrm{MWCNTs}$ методами XANES и XPS, а также особенностей морфологии, локальной атомной и электронной структуры нанокомпозита.

\section{Эксперимент}

Образцы нанокомпозитов $\mathrm{CuO}_{x} / \mathrm{MWCNTs}$ и наночастиц $\mathrm{CuO}_{x}$ были синтезированы методом, основанным 

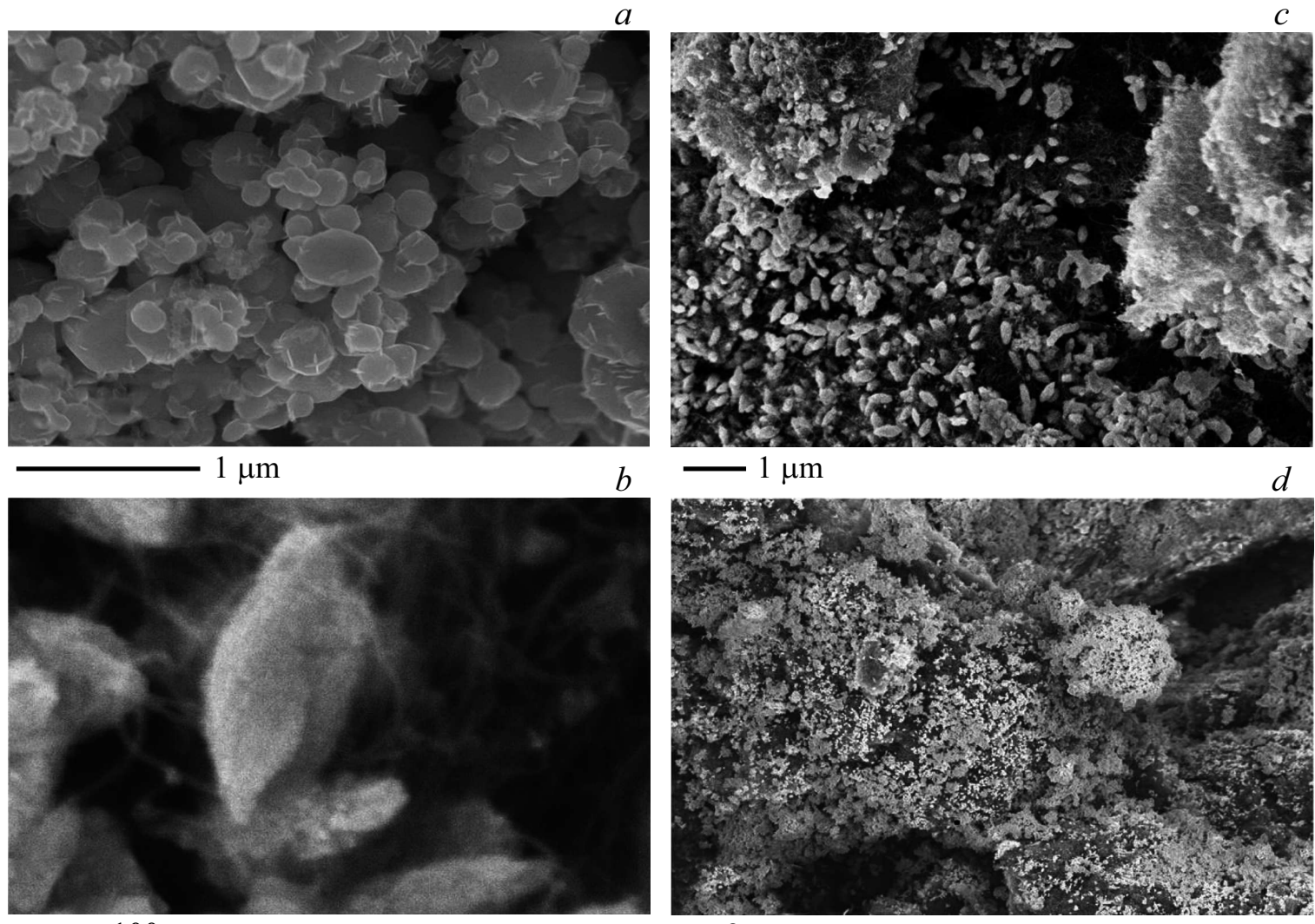

西

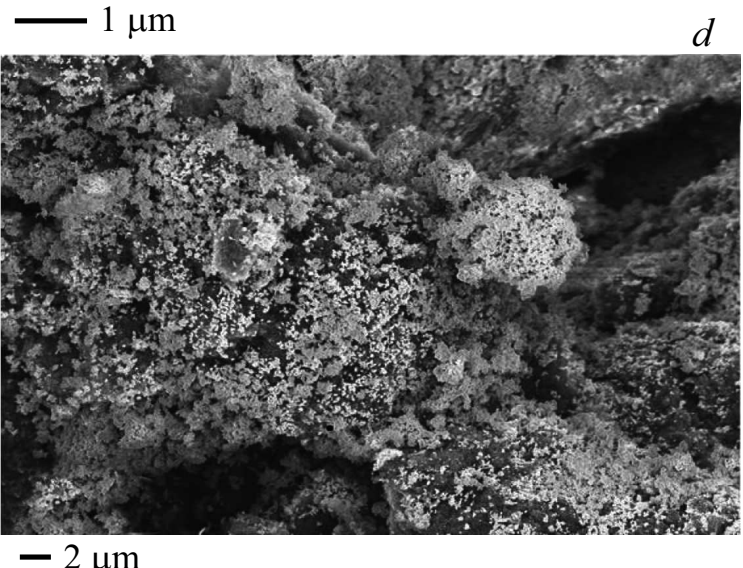

Рис. 1. Микрофотографии наночастиц $\mathrm{CuO}_{x}(a)$, нанокомпозита $\mathrm{CuO}_{x} / \mathrm{MWCNTs}$ в размерных шкалах: $100 \mathrm{~nm}(b), 1 \mu \mathrm{m}(a, c)$, $2 \mu \mathrm{m}(d)$.

на электрохимическом окислении и диспергировании металла при наложении импульсного переменного тока в щелочном растворе [15]. Медные электроды были погружены в водный раствор хлорида натрия с концентрацией $2 \mathrm{~mol} / \mathrm{L}$, при которой наблюдалась наибольшая скорость окисления и разрушения меди, а также отсутствовало ее растворение, о чем свидетельствовали результаты рентгенофлуоресцентного анализа растворов после синтеза. Плотность переменного симметричного тока составляла $1.0 \mathrm{~A} \cdot \mathrm{cm}^{-2}$, с соотношением амплитуд катодных и анодных импульсов $J_{c}: J_{a}=1: 1$. При синтезе нанокомпозита в раствор добавляли высокоочищенные многостенные углеродные нанотрубки (MWCNTs) с диаметром в диапазоне 7-10 nm, прошедшие дегазацию в атмосфере гелия при температуре $300^{\circ} \mathrm{C}$ в течение $2 \mathrm{~h}$.

Микрофотографии нанокомпозитов $\mathrm{CuO}_{x} / \mathrm{MWCNTs}$ и наночастиц $\mathrm{CuO}_{x}$ были получены на микроскопах Supra 25 и LEO 1560 VP (Zeiss) соответственно.

Экспериментальные спектры рентгеновского поглощения NEXAFS C1s и рентгеновские фотоэлектронные спектры (XPS) были получены в РоссийскоГерманской лаборатории (RGL) синхротронного центра BESSY II (HZB, Германия, Берлин). Спектры NEXAFS $\mathrm{C} 1 s$ были зарегистрированы в энергетическом интервале
$280-320 \mathrm{eV}$ в режиме регистрации полного электронного выхода [16]. Такой режим регистрации позволяет эффективно проводить исследования наноразмерных объектов без их разрушения и модификации и получать информацию об атомно-химическом составе и электронном строении в приповерхностном слое образца [17]. Размер сфокусированного пятна на образце составлял $\sim 0.2 \times 0.1 \mathrm{~mm}$. Ток в кольце поддерживался $\sim 280 \mathrm{~mA}$. Рентгеновские фотоэлектронные спектры были зарегистрированы с использованием полусферического анализатора Phobos 150. Измерения проводились в режиме регистрации нормальной фотоэмиссии в сверхвысоком вакууме $\left(\sim 10^{-9}-10^{-10}\right.$ Torr $)$. Энергия квантов составляла $1030 \mathrm{eV}$.

Измерения XANES спектров Cu1s проводились путем регистрации выхода рентгеновской флуоресценции на станции KMC-2 синхротронного центра BESSY II (HZB, Германия, Берлин). Величина щели составила $800 \mu \mathrm{m}$, ток в кольце поддерживался $\sim 280 \mathrm{~mA}$. Размер сфокусированного пятна на образце составлял $\sim 0.2 \times 0.1 \mathrm{~mm}$. Одновременно со спектрами поглощения наночастиц и композитов записывались спектры медной фольги. Обработка спектров (вычитание фона, нормировка) производилась в программе Athena [18]. 


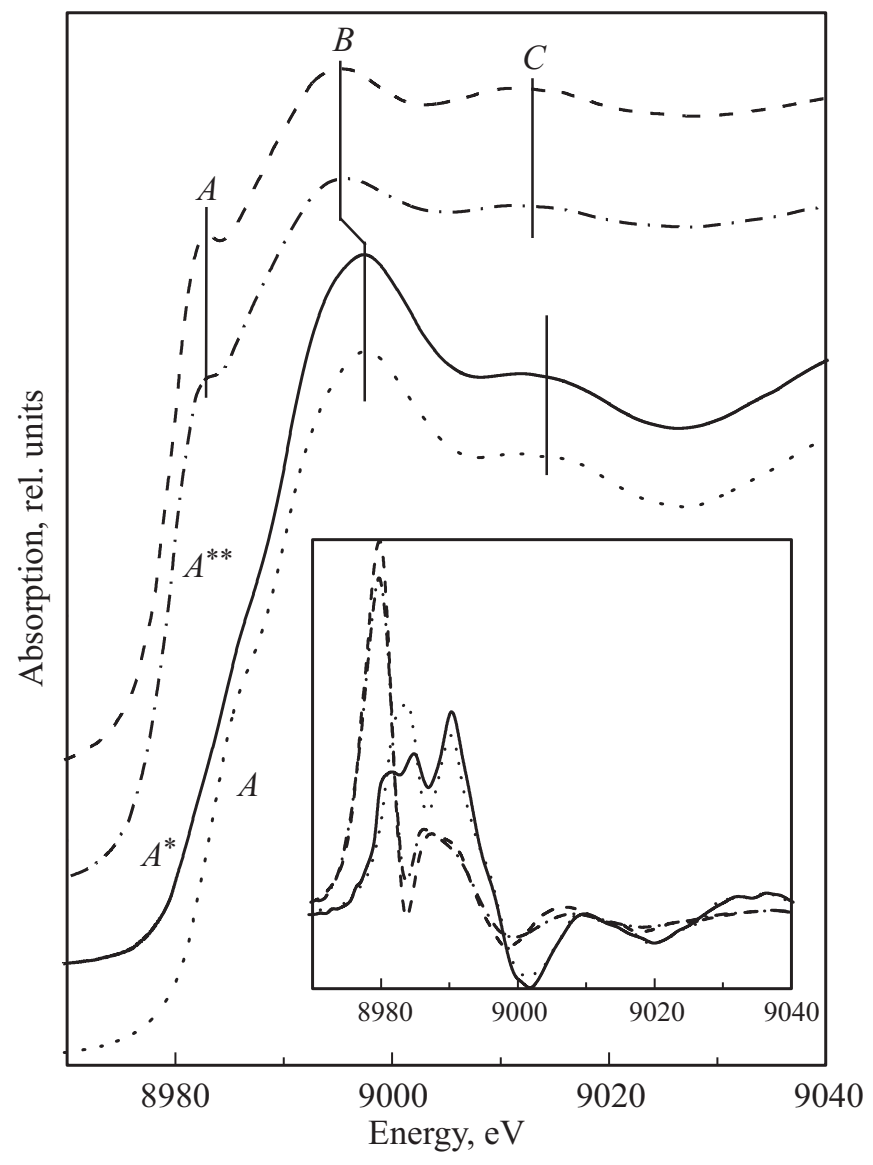

Рис. 2. Спектры XANES Cu1s-наночастиц $\mathrm{CuO}_{x}$ (штрих-пунктирная линия) и нанокомпозита $\mathrm{CuO}_{x} / \mathrm{MWCNTS}$ (сплошная линия) в сравнении со стандартными соединениями $\mathrm{CuO}$ (пунктир) и $\mathrm{Cu}_{2} \mathrm{O}$ (штриховая линия). Вставка - первая производная спектров XANES Cu1s.

\section{Результаты и обсуждения}

Результаты анализа нанокомпозита $\mathrm{CuO}_{x}$ /MWCNTs методом сканирующей электронной микроскопии (SEM) приведены на рис. $1, b, c, d$. Известно, что SEM позволяет оценить морфологию массивных образцов углеродных нанотрубок и композитов на их основе. На микрофотографиях видно, что массив нанотрубок равномерно покрыт многочисленными чешуйчатообразными структурами $\mathrm{CuO}_{x}$ с размерами в диапазоне $200-500 \mathrm{~nm}$. Для сравнения на рис. 1, $a$ приведена микрофотография чистых (без добавления нанотрубок) наночастиц $\mathrm{CuO}_{x}$, полученных при аналогичных условиях синтеза [19]. Видно, что морфология чистых наночастиц $\mathrm{CuO}_{x}$ и наноструктурированного $\mathrm{CuO}_{x}$ в составе композита различается.

На рис. 2 представлены экспериментальные XANES $\mathrm{Cu} 1 s$-спектры нанокомпозита $\mathrm{CuO}_{x} / \mathrm{MWCNTs}$ в сопоставлении со спектрами чистых наночастиц $\mathrm{CuO}_{x}$ и реперных соединений оксидов $\mathrm{Cu}_{2} \mathrm{O}$ и $\mathrm{CuO}$. Спектры поглощения $\mathrm{Cu} 1 s$ обусловлены переходами $1 s$-электронов меди на свободные $4 p$-состояния. Спектральные особенности $A$ на спектрах оксидов $\mathrm{Cu}_{2} \mathrm{O}$ и $\mathrm{CuO}$ формируются в результате переходов $1 s$-электронов в зону свободных состояний $-4 p \pi$, основной максимум пик $B$ (белая линия) обусловлен переходами $1 s$ в зону свободных состояний $4 p \sigma[20,21]$. Спектр XANES Cu1s нанокомпозита $\mathrm{CuO}_{x} / \mathrm{MWCNTs}$ по положению края поглощения, форме, энергетическому положению и интенсивности спектральных особенностей $B, C$ совпадает со спектром оксида меди $\mathrm{CuO}$. Это свидетельствует о том, что наноструктурированный $\mathrm{CuO}_{x}$, покрывающий нанотрубки, формируется преимущественно двухвалентным оксидом меди $\mathrm{CuO}$. Однако, на кривых первых производных спектров $\mathrm{CuO}_{x} / \mathrm{MWCNTs}$ и $\mathrm{CuO}$ (вставка на рис. 2) отчетливо видны различия в диапазоне энергий 8980-8990 eV. Они проявляются в расщеплении плеча $A$ в спектре нанокомпозита на две слабоинтенсивные особенности $A^{*}$ и $A^{* *}$ и связаны с модификацией зоны $4 p \pi$ [20]. Наличие особенности $A^{*}$ на энергии около $8981 \mathrm{eV}$ позволяет идентифицировать небольшую примесь одновалентных ионов меди [22]. Сдвиг пика $A^{* *}$ относительно пика $A$ в спектре $\mathrm{CuO}$ на $1 \mathrm{eV}$ говорит о различном переносе заряда медь-кислород в нанокомпозите и оксиде.

Кроме того, сопоставление XANES Cu1s спектров $\mathrm{CuO}_{x} / \mathrm{MWCNTs}$ и чистых наночастиц $\mathrm{CuO}_{x}$ говорит об изменении локальной атомной и электронной структуры $\mathrm{CuO}_{x}$ в составе нанокомпозита. Так, из рисунка видно, что форма и энергетическое положение всех спектральных особенностей в спектре $\mathrm{Cu} 1 s$ чистых наночастиц $\mathrm{CuO}_{x}$ говорит о преимущественном содержании одновалентного оксида меди и присутствии небольшой примеси двухвалентных ионов меди в данных образцах [19]. Таким образом, добавление нанотрубок при синтезе $\mathrm{CuO}_{x} / \mathrm{MWCNTs}$ приводит к изменению морфологии, локальной атомной и электронной структур наноструктурированного $\mathrm{CuO}_{x}$ при контакте с нанотрубкой. При образовании нанокомпозита преимущественное валентное состояние меди изменяется с $1+$ на $2+$.

На рис. 3 представлены NEXAFS спектры C1s исходных MWCNTs, в сопоставлении со спектром нанокомпозита $\mathrm{CuO}_{x} / \mathrm{MWCNTs}$.

Тонкая структура спектров поглощения NEXAFS $\mathrm{C} 1 s$ формируется в результате разрешенных дипольными правилами отбора переходов $1 s$-электронов атомов углерода в свободные состояния зоны проводимости $2 p$. Спектр поглощения углеродных трубок характеризуется наличием двух областей: $\sigma$-резонанс-область энергий выше $289 \mathrm{eV}$, спектральные особенности этой области обусловлены электронными переходами в $2 p_{x, y}$-электронные состояния; $\pi$-резонанс-область энергий $\sim 285 \mathrm{eV}$, эта особенность обусловлена электронными переходами в $2 p_{z}$-состояния. Изменения в области $\pi$-резонанса и в межрезонансной области помогают идентифицировать появление новых химических связей при функционализации нанотрубок [23,24]. 


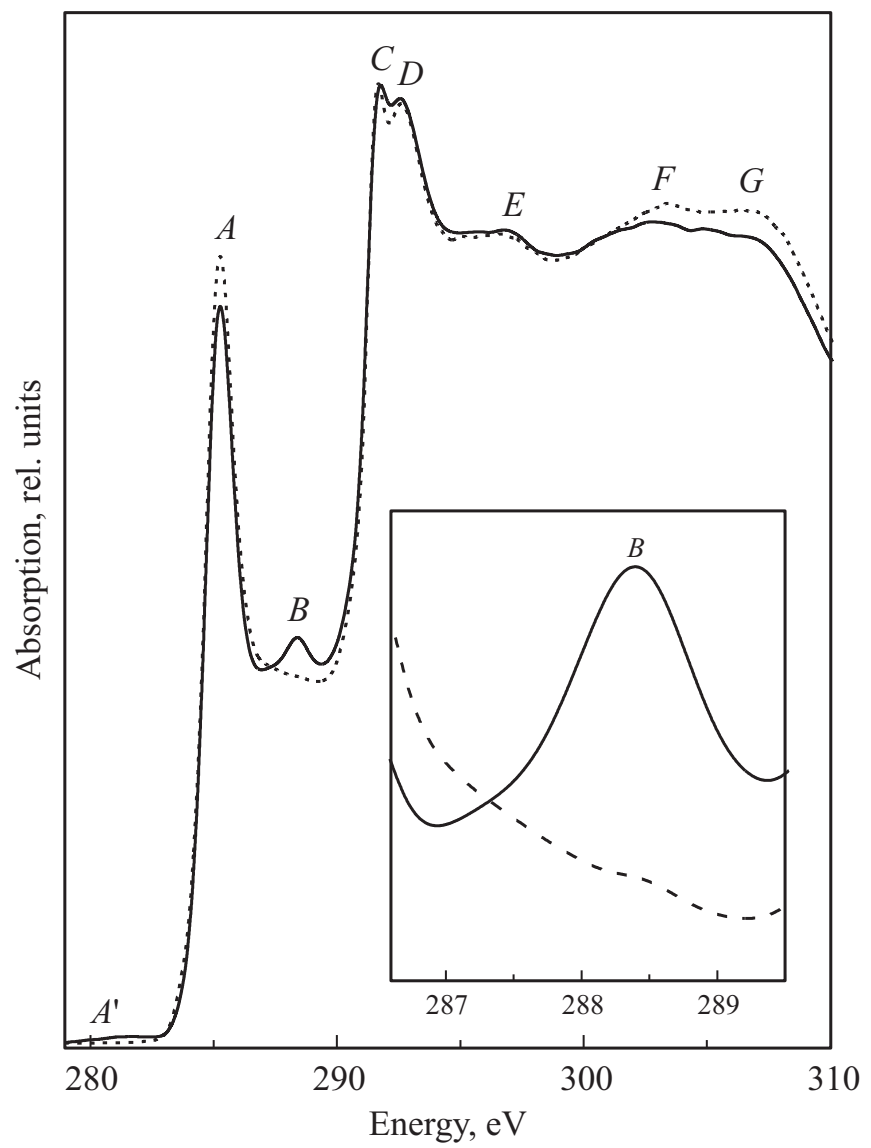

Рис. 3. Спектры $\mathrm{C} 1 s$ NEXAFS нанокомпозита $\mathrm{CuO}_{x} / \mathrm{MWCNTS}$ (сплошная линия) и исходных нанотрубок MWCNTs (штриховая линия). Вставка - межрезонансная область.

По форме, наличию и энергетическому положению основных спектральных особенностей (пики $A, C-G$ ) спектры исходных нанотрубок и $\mathrm{CuO}_{x} / \mathrm{MWCNTs}$ схожи между собой и согласуются со спектрами MWCNTs, опубликованными ранее $[9,23]$. В спектрах наблюдается две области: $\pi$-резонанс - узкая полоса на энергии $285.3 \mathrm{eV}$ (пик $A$ ), обусловленный переходами электронов с $1 s$ в свободные $2 p_{z}$-состояния $\pi^{*}$-симметрии и протяженный $\sigma$-резонанс (пики $C-G$ ), обусловленный переходами $1 s$-электронов в свободные гибридные $2 s 2 p_{x, y}$-состояния $\sigma^{*}$-симметрии. Из рис. 3 видно, что $\mathrm{C} 1 s$-спектр нанокомпозита сохраняет все основные спектральные особенности ( $\pi$ - и $\sigma$-резонансы), характерные для спектра исходных нанотрубок. Это говорит об отсутствии значительного разрушения структуры слоев нанотрубок при формировании нанокомпозита [23]. К различиям спектра $\mathrm{CuO}_{x} / \mathrm{MWCNTs}$ и спектра исходных MWCNTs следует отнести уменьшение интенсивности $\pi$-резонанса (пик $A$ ), обусловленное уменьшением плотности свободных $2 p_{z}$-состояний. Это отражает расходование $\pi$-электронов углеродных атомов трубок на образование ковалентных связей с атомами наноструктурированного $\mathrm{CuO}_{x}$. Вместе с тем в спектре нанокомпозита наблюдается максимум в межрезонансной области (пик $B$ ), соответствующий углерод-кислородным химическим связям [23] и обусловленный взаимодействием наноструктурированного $\mathrm{CuO}_{x}$ c MWCNTs [9]. При этом, вероятно, в местах контакта наноструктурированного $\mathrm{CuO}_{x}$ и нанотрубок образуются участки $s p^{3}$-гибридизациии. В пользу данного факта говорит и размытие тонкой структуры в области $\sigma$-резонанса [25]. Появление в спектре нанокомпозита новой слабоинтенсивной особенности в области $\pi$-резонанса со стороны низких энергий $(\sim 281 \mathrm{eV})$ также указывает на химическое связывание между компонентами нанокомпозита путем гибридизации валентных электронных состояний атомов наноструктурированного $\mathrm{CuO}_{x}$ и MWCNTs.

Таким образом, в нанокомпозите $\mathrm{CuO}_{x} / \mathrm{MWCNTs}$ наблюдается взаимодействие нанотрубок и наноструктурированного $\mathrm{CuO}_{x}$ с образованием ковалентных углеродкислородных связей.

Взаимодействие наноструктурированного $\mathrm{CuO}_{x}$ с MWCNTs подтверждается и данными XPS анализа. На pис. 4 приведены XPS C1s-линии нанокомпозита и мас-

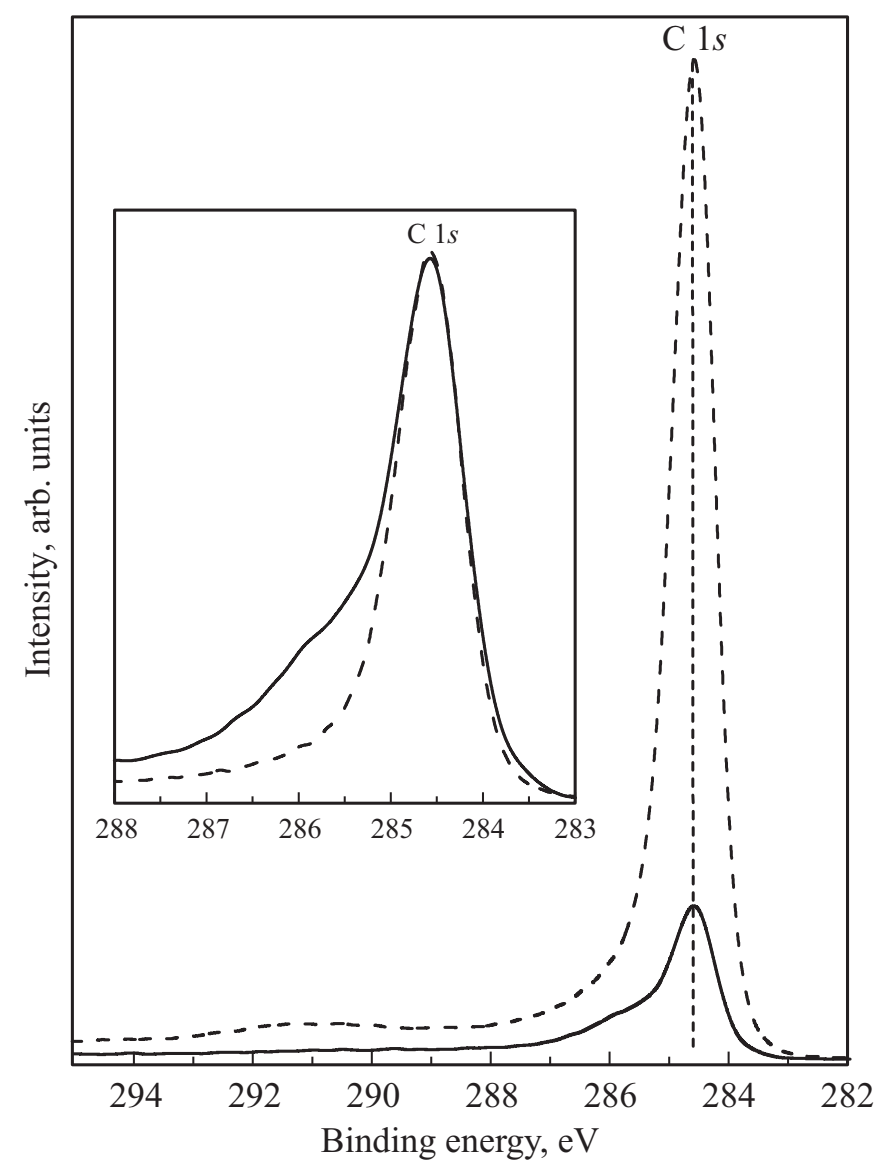

Pис. 4. XPS $\mathrm{C} 1 s$ нанокомпозита $\mathrm{CuO}_{x} / \mathrm{MWCNTs}$ (сплошная линия) в сопоставлении с исходными трубками MWCNTs (штриховая линия). На вставке для удобства сравнения интенсивность линии $\mathrm{C} 1 s \mathrm{CuO}_{x} / \mathrm{MWCNTs}$ увеличена в 6.5 раз. 
сива исходных нанотрубок. Уменьшение интенсивности $\mathrm{C} 1 s$-линии нанокомпозита по сравнению со спектром исходных нанотрубок обусловлено тем, что часть поверхности трубок покрыта наноструктурированным $\mathrm{CuO}_{x}$. Основной пик при энергии связи $284.4 \mathrm{eV}$ относится к атомам углерода в состоянии $s p^{2}$-гибридизации, плечи на энергии 285.3, 286.8 eV соответствуют атомам углерода с $s p^{3}$-гибридизацией и атомам углерода, связанными с кислородными атомами. Для наглядности изменений в спектре на вставке рис. 4 показан спектр нанокомпозита, нормализованный по интенсивности с основным пиком спектра чистых нанотрубок. Рост плеча со стороны больших энергий связи говорит о росте количества атомов углерода с $s p^{3}$-гибридизацией и обусловлен присутствием хемосорбированных атомов и комплексов. Кроме этого, в спектре композита практически исчезает сателлит $\pi-\pi^{*}$ на энергии выше $289 \mathrm{eV}$, который появляется за счет свободных $\pi$-электронов и характерен для соединений с $s p^{2}$-гибридизацией. Это также свидетельствует об увеличении доли $s p^{3}$-гибридизованных атомов углерода и снижению концентрации делокализованных $\pi$-электронов.

\section{Заключение}

Рентгеноспектральными методами XANES, XPS и методом SEM было исследовано межфазное взаимодействие в нанокомпозите $\mathrm{CuO}_{x} / \mathrm{MWCNTs}$, синтезированном методом электрохимического окисления и диспергирования металла при наложении импульсного переменного тока в щелочном растворе. Анализ XANES Cu1s-спектров чистых наночастиц и наноструктурированного $\mathrm{CuO}_{x}$ в составе нанокомпозита показал, что в процессе образования нанокомпозита происходит изменение валентного состояния меди от +1 до +2 , при одновременном изменении морфологии $\mathrm{CuO}_{x}$. Установлено, что наноструктурированный $\mathrm{CuO}_{x}$ в нанокомпозите $\mathrm{CuO}_{x} / \mathrm{MWCNTs}$ образован преимущественно $\mathrm{CuO}$ и представляет собой чешуйчатообразные частицы размера 200-500 nm, равномерно диспергированные по массиву нанотрубок. При формировании нанокомпозита не наблюдалось значительной деструкции внешних слоев углеродных нанотрубок. На межфазных границах нанокомпозита наблюдается химическое взаимодействие $\mathrm{CuO}_{x}$ и нанотрубок с образованием ковалентных углерод-кислородных связей.

Работа выполнена при финансовой поддержке Внутреннего гранта ЮФУ ВнГр-07/2017-30.

Авторы выражают благодарность Берлинскому центру синхротронного излучения Bessy II (станции КМС-2, RGL) за предоставление пучкового времени, а также M.M. Бржезинской и И.Н. Леонтьеву за проведение СЭМ измерений.

\section{Список литературы}

[1] Wen Z.B., Yu F., You T., Zhu L., Zhang L., Wu Y.P. // Mater. Res. Bull. 2016. V. 74. P. 241.

[2] Wang H., Liang Y., Gong M., Li Y., Chang W., Mefford T., Zhou J., Wang J., Regier T., Wei F., Dai H. // Nat. Commun. 2012. V. 3. P. 917.

[3] Zheng J., Zhang Q., He X., Gao M., Ma X., Li G. // Proc. Engin. 2012. V. 36. P. 235.

[4] Pannopard P., Khongpracha P., Probst M., Limtrakul J. // J. Molecular Graphics and Modelling. 2009. V. 28. P. 62.

[5] Shitole K.D., Nainani R.K., Thakur P. // Defence Science J. 2013. V. 63. N 4. P. 435.

[6] Gong M., Zhou W., Tsai M.-C., Zhou J., Guan M., Lin M.C., Zhang B., Hu Y., Wang D.-Y., Yang J., Pennycook S.J., Hwang B.-J., Dai H. // Nat. Commun. 2014. V. 5. P. 4695.

[7] Salunkhe R.R., Lin J.J., Malgras V., Dou S.X., Kim J.H., Yamauchi Y. // Nano Energy. 2015. V. 11. P. 211.

[8] Wang X., Zhang F., Xia B., Zhu X., Chen J., Qiu S., Zhang P., Li J. // Sol. Stat. Sci. 2009. V. 11. P. 655.

[9] Несов С.Н., Болотов В.В., Корусенко П.М., Поворознюк С.Н., Вилков О.Ю. // ФТТ. 2016. Т. 58. № 5. Р. 966; Nesov S.N., Bolotov V.V., Korusenko P.M., Povoroznyuk S.N., Vilkov O.Yu. // Phys. Sol. State. 2016. V. 58. N 5. P. 997.

[10] Yalovega G.E., Myasoedova T.N., Shmatko V.A., Brzhezinskaya M.M., Popov Yu.V. // Appl. Surf. Sci. 2016. V. 372. P. 93.

[11] Shmatko V., Leontyeva D., Nevzorova N., Smirnova N., Brzhezinskaya M., Yalovega G. // J. Electron Spectroscopy and Related Phenomena. 2017.

doi 10.1016/j.elspec.2017.03.016

[12] Авакян Л.А., Манукян А.С., Мизарханян А.А., Шароян Е.Г., Зубавичус Я.В., Тригуб А.Л., Колпачева Н.А., Бугаев Л.А // Опт. и спектр. 2013. Т. 114. № 3. С. 383; Avakyan L.A., Manukyan A.S., Mirzakhanyan A.A., Sharoyan E.G., Zubavichus Ya.V., Trigub A.L., Kolpacheva N.A., Bugaev L.A. // Opt. Spectrosc. 2013. V. 114. N 3. P. 347.

[13] Солдатов А.В., Кравцова А.Н., Родина И.С., Мансур А.Н. // Опт. и спектр. 2004. Т. 96. № 6. С. 929; Soldatov A.V., Kravtsova A.N., Rodina I.S., Mansur A.N. // Opt. Spectrosc. 2004. V. 96. N 6. P. 853.

[14] Яловега Г.Э., Солдатов А.В. // Опт. и спектр. 1998. Т. 85. № 6. C. 979; Yalovega G.E., Soldatov A.V. // Opt. Spectrosc. 1998. V. 85. N 6. P. 898.

[15] Kuriganova A.B., Leontyeva D.V., Ivanov S., Bund A., Smirnova N.V. // J. Appl. Electrochem. 2016. V. 46. P. 1245.

[16] Gudat W., Kunz C. // Phys. Rev. Lett. 1972. V. 29. P. 169.

[17] Месилов В.В., Галахов В.Р., Гижевский Б.А., Семенова А.С., Келлерман Д.Г., Raekers M., Neumann M.3. // ФTT. 2013. T. 55. № 5. C. 866; Mesilov V.V., Galakhov V.R., Gizhevskii B.A., Semenova A.S., Kellerman D.G., Raekers M., Neumann M. // Phys. Solid State. 2013. V. 55. N 5. P. 943.

[18] Ravel B., Newville M. // J. Synchrotron Rad. 2005. V. 12. P. 537.

[19] Ulyankina A., Leontyev I., Maslova O., Allix M., Rakhmatullin A., Nevzorova N., Valeev R., Yalovega G., Smirnova N. // Mater. Sci. Semicond. Process. 2018. V. 73. P. 111.

[20] Wijesundera R.P., Hidaka M., Koga K., Choi J.-Y., Sung N.E. // Ceramics-Silikáty. 2010. V. 54 N 1. P. 19. 
[21] Gaur A., Shrivastava B.D. // Acta Physica Polonica A. 2012. V. 121 N 3. P. 647.

[22] Liu H., Zeng F., Gao S., Wang G., Song C., Pan F. // Phys. Chem. Chem. Phys. 2013. V. 15. P. 13153.

[23] Сивков В.Н., Объедков А.М., Петрова О.В., Некипелов С.В., Кремлев К.В., Каверин Б.С., Семенов Н.М., Гусев С.A. // ФТТ. 2015. Т. 57. № 1. С. 185; Sivkov V.N., Ob"edkov A.M., Petrova O.V., Nekipelov S.V., Kremlev K.V., Kaverin B.S., Semenov N.M., Gusev S.A. // Phys. Sol. State. 2015. V. 57. N 1. P. 197.

[24] Brzhezinskaya M., Shmatko V., Yalovega G., Krestinin A., Bashkin I., Bogoslavskaja E. // J. Electron Spectroscopy and Related Phenomena. 2014. V. 196. P. 99-103.

[25] Болотов В.В., Несов С.Н., Корусенко П.М., Поворознюк C.H. // ФТТ. 2014. Т. 56. № 9. C. 1834; Bolotov V.V., Nesov S.N., Korusenko P.M., Povoroznyuk S.N. Phys. Sol. State. 2014. V. 56. N 9. P. 1899. 